\title{
A Primeira República muito além do café com leite
}

\author{
Antonio Luigi Negro* \\ Jonas Brito ${ }^{* *}$
}

VISCARDI, Cláudia. O teatro das oligarquias: uma revisão da "política do café com leite". Belo Horizonte: Fino Traço, 2012.

Em seu livro $O$ teatro das oligarquias, contestando a validade da tese do café com leite por meio do exame das articulaçóes referentes às sucessóes presidenciais - em que nota "os arranjos políticos mais importantes” (p. 25) —, Cláudia Viscardi demonstra como diversos atores se alinharam e desalinharam nas disputas ocorridas por ocasião da substituição dos mandatos presidenciais ocorridos entre Rodrigues Alves (19021908) e Washington Luís (1926-1930). Para tal, ela fez uso da hipótese da estabilidade do primeiro regime republicano ter sido fornecida pela "instabilidade" (p. 25) das alianças entre atores como o Exército, o Poder Executivo e os seis estados mais fortes (São Paulo, Minas Gerais, Rio Grande do Sul, Bahia, Pernambuco e Rio de Janeiro).

Viscardi consegue demonstrar que o predomínio dos vencedores nas sucessôes não se eternizava à custa da marginalidade dos demais atores. No lugar disso, a expectativa do rodízio das forças ao término de cada mandato, os efeitos das disputas e o esforço dos competidores no sentido de impedir a monopolização do poder por um ou outro ator asseguravam a crença em campanhas futuras, inibiam o ressentimento de exclusão entre os perdedores e, nesse sentido, continham rupturas.
Logo, São Paulo e Minas não fizeram (a despeito dos demais) o que bem entendiam. Ao contrário, havia intensa barganha entre os estados.

É bom que se diga que não são desconsideradas as posiçóes, na economia, bem como na política, de mineiros e paulistas. A autora igualmente não ignora que se coligaram e que ocuparam juntos a administração federal. No segundo capítulo é mostrado ao leitor que Minas Gerais, uma vez resolvidos seus problemas internos - na sucessão de Rodrigues Alves (a partir de 1905) conseguiu alçar-se ao primeiro plano da política (p. 72, 87), lugar já pertencente aos paulistas desde 1889 (em aliança com militares ou baianos). Ao mesmo tempo, o livro faz ver que os demais estados sabiam - todo o tempo - que uma aliança exclusivista entre Minas e São Paulo lhes seria prejudicial. Em segundo lugar, o Exército e o Executivo também agiam, tornando o processo e as redes que o compunham muito mais complexos e multifacetados. Logo, ante os planos situacionistas, houve, ao longo das sucessóes, a composição de eixos alternativos de poder, com dose respeitável de eficácia política. Ainda mais (e isto é absolutamente notável), não é apenas o fato de mineiros e paulistas não serem os únicos com voz e vez; é também o fato de inexistir permanente "aliança entre os dois". Na prática, afirma Viscardi, "mais se temiam do que se uniam" (p. 253). Sem negar as aproximaçôes, a autora demonstra amplamente

\footnotetext{
* Doutor em história pela Universidade de Campinas (Unicamp), professor associado da Universidade Federal da Bahia (UFBa), pesquisador de produtividade científica do CNPq, nível 2. Salvador, BA, Brasil. E-mail: negro@ufba.br.

** Graduado em história pela Universidade Federal da Bahia (UFBa) e mestrando em história pela mesma instituição. Salvador, BA, Brasil. E-mail: jonasbrito88@hotmail.com.
} 
que, em vez de solidez e confiança, havia rupturas e receios mútuos. Portanto, é necessário notar no capítulo final (o oitavo) que, quando a política ficou apenas nas mãos de mineiros e paulistas (década de 1920), mais a Primeira República sofreu com as investidas de monopolização e continuísmo, até chegar a hora em que Sáo Paulo deixou de "levar em conta o poder político do estado de Minas" (p. 314), confirmando as suspeitas dos mineiros sobre a parceria não ser durável.

Tese de doutorado defendida em 1998 no Programa de Pós-Graduação em História da Universidade Federal do Rio de Janeiro (UFRJ), O teatro das oligarquias - em sua segunda edição (a primeira é de 2001, lida e esgotada rapidamente) — é uma contribuição importante à historiografia da Primeira República. Ao explicar como veio a explorar as desavenças de mineiros e paulistas, Viscardi cita (dentre outros) o coreano Eul Soo-Pang e seu livro Coronelismo e oligarquias (1889-1934). A Bahia na Primeira República brasileira, em particular o comentário sobre quáo proveitoso seria pensar em "café contra o leite" (p. 46). É nesta altura que ela atesta ao leitor que não irá apenas investigar os impedimentos da aliança de Minas e São Paulo. Outrossim, irá questionar a existência dessa aliança, nos termos a que estamos habituados: praticamente uma rotina, um dado da realidade. Para tal, ao ter em mira os acordos entre mineiros e paulistas, apela-se também à história econômica, sendo relativizado o peso da produção leiteira de Minas Gerais, já que o estado era o segundo maior produtor da cafeicultura nacional até o fim dos anos 1920. Apesar de "Minas e Sáo Paulo serem produtores de café" e, durante a administração de Artur Bernardes, "estarem governando o país em aliança política, seus interesses não eram os mesmos". Nesse ponto, volta o livro à sua tese: "Minas Gerais via Sáo Paulo mais como um parceiro a ser temido do que um aliado plenamente confiável” (p. 291). Logo, o convênio desses dois atores não era durável, sólido, nem estava baseado em reciprocidade. Não houve rodízio e nem tampouco os demais atores assistiam a tudo impotentes ou em paralisia.

Esta segunda edição chega em boa hora, pois de há muito que a primeira edição esgotou-se. In- felizmente, deixando de aquilatar o momento, a prática de boa parte das casas editoriais brasileiras de imprimir originais sem maior esmero de preparo e revisão deixa de produzir um livro com índice onomástico e de assuntos e lugares. É de se esperar que uma editora trate um livro adequadamente, contribuindo para identificar e rever lacunas e arestas que, durante a redação, fugiram do olhar meticuloso da autoria. Seria uma contribuiçáo verdadeiramente editorial oferecer uma parceria, indo além dos vezeiros vetos aos agradecimentos e às notas de pé de página, que aliás interessam ao público leitor das universidades (consistindo este em parte expressiva do mercado consumidor). Igualmente, seria uma contribuição substantiva a um livro que, afora ser bem organizado, com cada capítulo sendo resumido no seu início, se faz entender com o uso de tabelas, gráficos e imagens.

Por um lado, em certas passagens, indicar nome e data, ou informar o cargo e a base política de um personagem menos notório, permitiria perceber, com mais inteireza e detalhe, o jogo entre os estados, realçando o mote do livro, que é a intensa disputa e sua consequente instabilidade, sinônimo - aqui - de imprevisibilidade, de ausência de garantias para as duas unidades mais fortes, seja econômica, seja politicamente (Sáo Paulo e Minas). José Marcelino, por exemplo, é uma referência que pede do leitor um grau mais avançado de intimidade com o assunto. $\mathrm{O}$ mesmo se diga do trecho em que são enumerados os casos de adesismo ao presidente Artur Bernardes, que assim neutralizou a oposição movida contra si nas eleições de 1921. "Na Bahia, uma disputa pela vaga senatorial, aberta com a morte de Rui Barbosa, opôs a facção seabrista ao Catete. Mas o velho líder baiano soube articular um acordo, negociando a indicação de um bernardista ao governo" (p. 288). Certamente, os leitores podem achar difícil para saber quando foi a morte de Rui (1923) e o pleito senatorial, que o velho líder baiano é J. J. Seabra, e que o bernardista é Pedro Lago.

Mesmo havendo uma diferença entre o clima de instabilidade da conjuntura e a frisada instabilidade inerente ao processo político analisado, ao discutir o processo sucessório de Artur Bernardes, 
um editor diligente teria chamado a atenção para o detalhe de o "clima de instabilidade" não favorecer "uma escolha compartilhada pelos diversos estados" (p. 294), o que, aparentemente, contraria o livro, segundo o qual a estabilidade do regime republicano era garantida pela instabilidade das alianças (mas nas páginas citadas a instabilidade ameaça o padrão sucessório).

Entre os caminhos que podem ser depreendidos do estudo do livro de Viscardi está a inovação na pesquisa histórica, a ser desdobrada nos estados. Por exemplo, ao assinalar que, na década de 1920, o modelo de sucessão presidencial passou a sofrer "sucessivas avarias", devendo-se seu esgotamento, principalmente, "às tentativas de monopolização por parte dos principais estados-atores" (p. 285), um pesquisador que se debruce sobre a história da Bahia na Primeira República tem a seu dispor mais de uma questão para esmiuçar. A primeira delas é buscar compreender quanto a política de acomodação das elites baianas - que consistia em monopolizar o poder continuamente (à custa da liquidação do rodízio entre as facçôes) fragilizou a Bahia no grupo dos seis estados mais importantes em nível nacional. Localmente, se as facçóes baianas não tinham motivos para acreditar na instabilidade do jogo, se possuíam razóes, em outras palavras, para esperar que os vencedores buscassem o absolutismo uma vez na situação, a saída esteve várias vezes no recurso a rupturas, causa de crises regulares. Esta marcante turbulência baiana desfavorecia sua posiçáo de destaque em nível nacional. E isto piorava por causa do assédio, como faz observar Viscardi, seja do senador gaúcho Pinheiro Machado, seja dos paulistas, haja vista que gaúchos e paulistas protestaram contra o número insatisfatório de cadeiras de suas respectivas bancadas, ameaçando diminuir as da Bahia. Nesse sentido, além de sua debilidade econômica, a Bahia perdeu espaço por não reproduzir, no nível da administração estadual, a regra de ouro do processo sucessório da Presidência da República, segundo a qual a situação não podia liquidar com as chances de a oposição subir ao poder. Ao falhar em obter a coesão de suas elites políticas, o estado perdia a chance de dispor de uma bancada "compactada no Congresso" (p. 54), "condição indispensável para a apropriação dos bens públicos".

Outra questão é as pesquisas subsequentes lidarem com o fato de que nem sempre a cronologia dos estados coincide com a cronologia nacional. Enquanto Artur Bernardes sufocou as oposiçôes e bloqueou a participaçáo de novos atores, desgastando o sistema político vigente, no Rio Grande do Sul, a subida de Getúlio Vargas à administraçáo estadual refletia a "uniáo interna de suas elites" (p. 76), inclusive com um mínimo de abertura para o proletariado participar (nos termos positivistas da ordem e do progresso). Em paralelo, enquanto, no nível nacional, o sistema político sofria danos, a Bahia, no plano local, conseguia manusear melhor seu traço negativo mais marcante (que era a política de acomodação da situação levar o jogo político a repetidos choques, inclusive armados). Não por acaso, no governo de Washington Luís, enquanto o Rio Grande do Sul forneceu a liderança mudancista, a Bahia forneceu a liderança conservadora (coligada a Sáo Paulo e, assim, lidando com as supracitadas queixas dos paulistas referentes ao número de cadeiras de sua bancada).

Uma terceira questão adicional está em notar a importância da regiáo Norte no processo político da Primeira República, quer para chapas de oposição, quer para chapas da situação, quer também para eleiçôes parlamentares. "O poder sobre os pequenos estados", afirma Viscardi, era alvo do "Rio Grande do Sul, especialmente os do norte e nordeste", o que, para os gaúchos, significava "peso significativo na federação", a ser somado à "sua histórica associação ao Exército" e, claro, à sua bancada federal e força econômica. Esta pretensão interestadual dos gaúchos, ela faz notar, contrariava o Leão do Norte —Pernambuco —, que também desejava para si "a posiçáo de centro, em torno do qual vagavam os satélites setentrionais” (p. 820).

Outros elementos devem ser examinados a respeito do Norte e sua relevância. $\mathrm{Na}$ sucessão do paraibano Epitácio Pessoa, a autora faz constar que o baiano J. J. Seabra "articulava uma frente dos estados do norte com o fim de eleger o sucessor". Em caso de insucesso, tais estados "apoiariam um nome comum para a Vice-Presidência". 
Esclarecendo as tratativas, Viscardi situa: "a partir da eleição de Epitácio, tornava-se possível aos pequenos estados terem pretensóes mais ambiciosas e tentarem até articular eixos alternativos de poder aos do centro-sul". Espertos que eram, "os mineiros estavam cientes de que Epitácio participava, junto à Bahia e Pernambuco, de tais articulaçôes" (p.270). Ainda a propósito do lugar dos nortistas na política brasileira, as duas campanhas presidenciais de Rui Barbosa (1910, 1919), mais a dobradinha J. J. Seabra e Nilo Peçanha na Reação Republicana (1921), afora a indicação de Miguel Calmon para vice-presidente junto com Washington Luís (depois retirada ante a necessidade de incluir Minas), quando somadas à candidatura à vice-presidência de Vital Soares em 1930 (que ganhou mas não levou) e à presidência de honra da Aliança Liberal oferecida ao mesmo J. J. Seabra - sem falar no fato de náo ter havido vice-presidentes do Sul e de, além do baiano Manuel Vitorino, ter havido um alagoano, dois pernambucanos e um maranhense vice-presidentes - , mostram que o jogo entre os estados passava pelos nortistas; algo que só repararemos sem os antolhos do café com leite.

O processo político extrapolava, como se vê, esta aliança - de ares absolutistas - entre mineiros e paulistas de tal modo que, mesmo sem uma economia forte, determinados estados conseguiram concorrer na política brasileira. Nesse sentido, é possível rever o lugar apagado e de paralisia conferido aos nortistas. Além de ser possível discernir esse lugar incomum do Norte, também será possível apreçar o peso das alianças entre litoral e sertão.

$O$ teatro das oligarquias consiste em exemplo inspirador para desdobramentos investigativos nos estados brasileiros, o que pode se verificar por meio de pesquisas de mestrado e doutorado nos diversos programas de pós-graduação hoje atuantes. Assim como Viscardi dirigiu sua curiosidade para os processos pré-eleitorais das campanhas presidenciais, é possível fazer o mesmo nos estados indo muito além não só do café com leite, mas também do determinismo econômico ou de versôes locais consagradas (porém, há muito tempo encanecidas pelo tempo). Em segundo lugar, as intervençóes federais nos estados fornecem oportunidade para os pesquisadores reverem o que sabemos sobre elas. Uma intervenção federal num estado, que pode ser tomada como sinal de instabilidade interna e fraqueza militar, poderá ser revista como uma dramática investida da Presidência para liquidar um obstáculo erguido pela atuação de um estado dissidente. A violência e o estremecimento institucional das intervençóes, no lugar de amostrarem estados débeis, podem indicar a tibieza do sistema republicano e democrático.

Adicionalmente, o livro permite à pesquisa livrar-se do pesadelo do paradigma paulista como destino necessário de todos os estados que falham em não se equiparar com São Paulo. $\mathrm{O}$ que Cláudia Viscardi faz é chamar a atenção para o excepcionalismo do estado bandeirante. Republicanismo histórico e sólido, cafeicultura, industrialização, finanças, transportes, imigração em massa, crescimento urbano e populacional: tudo isso foi conjugado de modo peculiar e não constitui modelo, mas sim experiência. Foi exatamente a avaliação de ser o mais importante, o mais rico, o mais forte, que levou Sáo Paulo, na sucessão de Washington Luís, "a abrir mão da aliança com os mineiros", evitando assim ter de "passar por mais um quatriênio submetido aos arbítrios de outro estado, econômica e politicamente mais frágil" (p. 306). Os paulistas ficaram fartos do jogo, querendo bancá-lo a sós. Contudo, o federalismo da Primeira República, do qual Sáo Paulo havia sido o expoente de primeira hora, supunha - conforme carta do presidente da Câmara dos Deputados Arnolfo Azevedo ao presidente Washington Luís em 1926 - um vínculo entre os jogadores cujo se desfazer era o fim do próprio jogo. "No baralho político há três ases e três reis". "Quem vai dirigir o jogo precisa ganhar a partida e para ganhá-la é indispensável ter dois ases e um rei" (sendo os ases Minas, São Paulo e Bahia, e os reis Pernambuco, Rio e Rio Grande do Sul). "Sentar-se à mesa do jogo sem contar com esses trunfos é arriscado e quem tiver a maioria absoluta dos seus valores fará, não só um governo bom, mas ótimo e fácil" (Carta, 26-4-1926. Arquivo Público do Estado de 
São Paulo. Arquivo Washington Luís. Caixa 188, pasta 1, documento 56). Estalado o processo mudancista, quando Washington Luís voltou-se para a Bahia tendo em vista a última esperança de obter respaldo político e militar, o Norte, com suas colunas revolucionárias, comandadas por moços tenentes, se infiltrou no território baiano pelo litoral e pelo sertão, para, num movimento de pinça, espremer à bala qualquer ato de solidariedade com o poder em queda.
Por abrir a valiosa oportunidade de enxergarmos melhor um tema táo sensível como o da disputa política no Brasil República, $O$ teatro das oligarquias é um livro que consegue ir além do círculo muitas vezes restrito dos especialistas e, assim, logra transmitir seus resultados — inéditos e originais - para estudantes, professores, estudiosos e interessados os mais diversos. Imediatamente, ao ser lido, remove antolhos e nos convida a abrir os olhos. 